\title{
IDOSOS E ALZHEIMER: CONTRIBUIÇÕES PARA UM ESTUDO DE CASO EM UM BANHEIRO DOMÉSTICO
}

\author{
MIRANDA, Gabriel (1); \\ YAMAGUCHI, Marcia (2); \\ CALSAVARA, Priscila (3); \\ BARROS, Bruno (4) \\ (1) Universidade Federal de Pernambuco, Graduando em Design \\ e-mail: gmsilvabg18@hotmail.com \\ (2) Universidade Federal de Pernambuco, Graduanda em Design \\ e-mail: marciayamaguchi@outlook.com \\ (3) Universidade Federal de Pernambuco, Graduanda em Design \\ e-mail: priscilacalsavara@hotmail.com \\ (4) Universidade Federal de Pernambuco, Mestre \\ e-mail: barros bruno@hotmail.com
}

\begin{abstract}
RESUMO
O Alzheimer é uma patologia que já acomete 1,2 milhão de brasileiros e esse número continua a aumentar. Sua ação é lenta e progressiva e causa prejuízos cognitivos, tais como perda de memória e raciocínio. Dentro deste contexto, esta pesquisa se propôs a abordar, em um estudo de caso, a utilização de um banheiro por idosos com Alzheimer, os quais, além das restrições da doença, também enfrentam o processo natural de envelhecimento. Para tanto, foi utilizada a Metodologia para Construção de Ambientes Centrados no Ser Humano. Como resultado, pôde-se gerar uma lista de requisitos ergonômicos para concepção de banheiros.
\end{abstract}

Palavras chave: ergonomia do ambiente construído; alzheimer; banheiro.

\begin{abstract}
Alzheimer's is a pathology that already affects 1.2 million Brazilians and this number continues to increase. The action of the disease is slow and progressive and causes cognitive impairments, such as memory loss and reasoning. In this context, this research proposed to address, in a case study, the use of a bathroom by elderly people with Alzheimer's, which, in addition to the restrictions of the disease, also face the natural aging process. For that, the Methodology for the Construction of Environments Centered on Human Being was used. As a result, it was possible to generate a list of ergonomic requirements for bathroom design.
\end{abstract}

Keywords: built environment ergonomics; alzheimer; WC. 


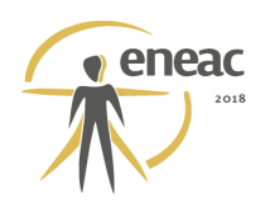

\section{INTRODUÇÃO}

Segundo a ABRAz (Associação Brasileira de Alzheimer), o Alzheimer é uma doença que acomete mais de 1,2 milhão de brasileiros e 35,6 milhões de pessoas no mundo, caracteriza-se pela perda de funções cognitivas (memória, orientação, atenção e linguagem), causada pela morte das células cerebrais. É uma enfermidade que não tem cura, mas pode e deve ser tratada, evitando assim pioras significativas. A doença possui três estágios, sendo de extrema importância identificar e tratá-la já no primeiro, pois quando diagnosticada desde o início são grandes as chances da doença não evoluir, o que muitas vezes não acontece por ser confundida com características comuns da velhice. Quando não acompanhada, o indivíduo pode piorar e a doença acaba entrando no segundo estágio, o que traz grandes impactos para a saúde do idoso, pois mesmo não tendo cura, o tratamento estabiliza o quadro e retarda a evolução dos sintomas. No terceiro estágio o indivíduo fica totalmente dependente, não consegue mais realizar, sozinho, simples atividades, como: comer, utilizar o banheiro, circular pela casa, não reconhece mais os familiares, é conhecido como estágio de demência.

Tendo como a base a informação de que o número de pessoas com Alzheimer tende a aumentar conforme os anos passam, é importante perceber a necessidade de se pensar em projetos que tenham como fundamento a preocupação com tal patologia. Dentro desse contexto, pode-se elevar o pensamento a todo tipo de espaço, doméstico ou não, com foco na promoção da autonomia do longevo. Um importante aspecto fragilizado pelo Alzheimer é o processo de higiene do enfermo. Muitos idosos perdem massa muscular pela falta de exercícios ou alimentos, além disto, sua imunidade vai sendo afetada. AS limitações relacionadas à higiene são relacionadas a limpar-se corretamente após fazer as necessidades fisiológicas ou mesmo conseguir fazê-las sozinhos. Um simples banho tornase complicado de ser realizado, principalmente quando o idoso o faz sozinho. Foi neste anseio de contribuir para um ambiente adequado que esta pesquisa repousou o foco, onde o banheiro domiciliar para idosos com Alzheimer foi o objeto de estudo essencial.

Nesta pesquisa, selecionou-se, como estudo de caso, um banheiro domiciliar o qual é concomitantemente utilizado por usuários saudáveis e uma idosa acometida por Alzheimer. Deste modo, foram abordados os aspectos resultantes da relação entre a idosa e o espaço. Acreditamos que pesquisas como esta possam estimular a promoção da autonomia de idosos através de subsídios teóricos que conduzam a elaboração de um espaço ergonomicamente adequado, os quais busquem soluções para os problemas cotidianos enfrentados por este público na utilização de banheiros domésticos.

\section{FUNDAMENTAÇÃO TEÓRICA}

Como afirma a OMS (2005), "a maioria das pessoas idosas que necessitam de cuidados prefere ser atendida em sua própria casa e, como a proporção de idosos aumenta mundialmente, viver em casa até uma idade mais avançada e com a ajuda de familiares irá se tornar cada vez mais comum". Este argumento da OMS tem se revelado deveras factível nos dias de hoje, 2018. A longevidade aumentou e o ambiente social/familiar para atender às necessidades, características e limitações do idoso precisa ser o foco para um convívio salutar do longevo.

Idosos com Alzheimer carregam suas particularidades etárias acrescidas da doença que o acomete, as quais influenciam diretamente na sua cognição. A cognição refere-se à capacidade de executar complexos processos mentais, como aprender, perceber, fazer decisões e lembranças (SMITH \& BUCKWALTER, 2005). Sendo assim, interpretar o ambiente é uma tarefa complexa, estrita e particularmente difícil, eventualmente, higienização e a alimentação ficam prejudicados. 


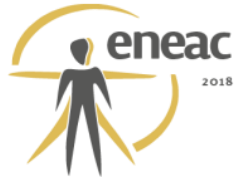

Uma forte característica do idoso que sofre com o Alzheimer é a afasia, uma característica que pode fazer o indivíduo omitir palavras. De modo geral, o longevo não entende o que sente e não sabe explicar o que é "conforto", por exemplo. Devido à percepção, linguagem e déficits de memória, pessoas com demência muitas vezes têm dificuldade em compreender e falar sobre as fontes de seu desconforto. Como resultado, eles geralmente expressam através de ações (SMITH \& BUCKWALTER, 2005).

Quando o enfermo reside com a família, acaba por interagir com os ambientes residenciais comuns a todos os demais membros, no entanto, a necessidade oriunda da doença atua como elemento dificultador, gerando diversas limitações e constrangimentos decorrentes do uso deste ambiente (SILVA e BARROS, 2016). Essa afirmação conclui a presença de um desafio de um ambiente confortável para indivíduos que possuam algum tipo de limitação, seja patológica ou de idade, sem um planejamento específico. Um ambiente que fora projetado sem as preocupações às limitações dos usuários acometidos de Alzheimer gera situações de constrangimento e risco aos idosos por não conseguirem utilizar o espaço.

Segundo Smith e Buckwalter (2005), o objetivo do cuidado para com o idoso se realça no princípio da busca do aumento da autoestima pessoal, promovendo dignidade ao indivíduo, conforto para si mesmo. Isso pode ser alcançado focando-se nas habilidades e sucessos daquela pessoa em sua vida. Desta forma, destacamos a ressalva de que este tipo de projeto torna-se único para os indivíduos. Neste contexto se insere a Ergonomia, que trata do estudo das interações das pessoas com a tecnologia, a organização e o ambiente, objetivando intervenções e projetos que visem melhorar de forma integrada e não dissociada a segurança, o conforto, o bem-estar e a eficácia das atividades humanas [...] (ABERGO, 2004). Logo, o campo das necessidades e limitações do ser humano é aplicado no contexto de ergonomia para ambientes a fim de proporcionar segurança, conforto e saúde física e mental aos usuários. O padrão internacional ISO (13407: 1999) especifica que o design dos sistemas centrado no ser humano deve ser baseado em uma clara compreensão das características dos usuários e das tarefas gerais que realizarão com o sistema. (ATTAIANESE e DUCA, 2010).

Considerando a tendência mundial do aumento da longevidade e o fato de que a Doença de Alzheimer continua sem uma cura definitiva, percebe-se que o número de afetados por essa doença, que já é a demência de maior incidência entre os idosos, tende a aumentar cada vez mais (SOUSA e MAIA, 2014). Portando, é imprescindível que hajam pesquisas e projetos voltados para idosos com Alzheimer o quanto antes, para servir de base para as futuras gerações e para a que se faz presente.

\section{METODOLOGIA}

A condução procedimental lançou mão da Metodologia para Projetos de Construção Centrados no Ser Humano, disseminada por Attaianese e Duca (2012). Neste estudo, utilizou-se das quatro primeiras etapas, a saber: Briefing de Design, Perfis de Usuários e Grupo de Ajuste, Análise da Tarefa e Adaptação às Necessidades dos Usuários.

$\mathrm{Na}$ etapa de Briefing de Design fez-se uma investigação para coletar informações do ambiente e de como o usuário o percebe no geral e em detalhes. Na segunda fase "Perfis de Usuários e Grupo de Ajuste", procurou-se identificar dados sobre os usuários diretos e indiretos do ambiente, para conhecer os perfis dos indivíduos que utilizam o espaço. No tópico seguinte, Análise da Tarefa, foram verificadas as atividades realizadas no ambiente, onde se observou as posturas adotadas, além de descritos os problemas que podem ser alavancados. Em acréscimo à investigação, incluíram-se aferições de iluminação, temperatura, ruídos e avaliação do esquema cromático do espaço. Por fim, na quarta fase, Adaptação às Necessidades dos Usuários, analisou-se os problemas destacados durante a 


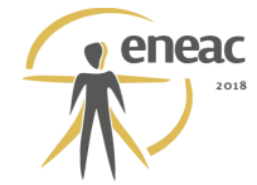

pesquisa e estabeleceram-se as Recomendações Ergonômicas para concepção do banheiro selecionado como estudo de caso, as quais podem ser generalizáveis para demais casos similares.

Além das etapas descritas anteriormente, acrescentou-se a avaliação do espaço de circulação do ambiente, lançado mão do Método de Avaliação da Circulação Horizontal Interna de Ambientes (MACHIA), descrito por Barros (2009), avaliação inserida na etapa de Análise da Tarefa. Neste estudo é importante considerar que a idosa não realiza toda a atividade sozinha, precisando de um espaço apropriado para ela e para sua cuidadora que, na maioria das vezes, estão juntas. Também foi acrescentada à investigação uma verificação antropométrica, no intuito de verificar as dimensões de alcance apropriadas para uma idosa.

\section{RESULTADOS}

\subsection{Briefing de Design}

O ambiente de pesquisa é um banheiro social. Seus componentes são: um chuveiro, um armário suspenso, um vaso sanitário, um espelho, uma cesta para roupa suja e alguns objetos nos cantos das paredes para auxiliar na disposição de utensílios de higiene. A janela que é a única entrada de ventilação e luz natural, ela é pequena e tem detalhes em listras. A janela se apresenta bem próxima ao teto. O teto do banheiro e seu único ponto de iluminação artificial. A laje, estruturando o telhado, faz com que a temperatura ambiente esteja sempre elevada, por vezes, até maior do que a temperatura fora da casa. O piso tem textura, sendo, de certa forma, antiderrapante. Não reflete muito a luz. Sua cor é próxima à cor das paredes. O banheiro é um local que recebe pouca iluminação natural e, embora exista luz, é uma luz indireta e, por vezes, insuficiente mesmo de dia, principalmente em dias nublados.

Figura 1- Banheiro selecionado para estudo de caso.
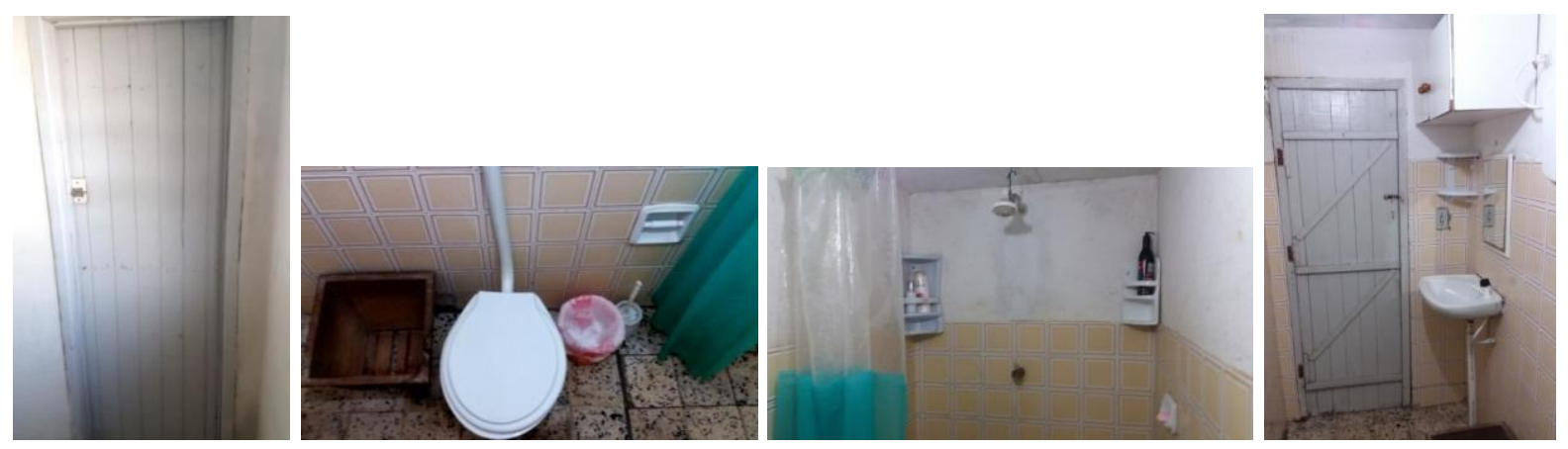

Fonte: Capturado pelos autores para a pesquisa.

A busca de informações sobre a percepção do ambiente fora feita com a usuária direta. Em se tratando do ruído, a usuária informa que dentro do ambiente consegue escutar muito do que acontece em outros lugares do domicílio, porém o que fala de dentro do banheiro não é escutado lá fora. A temperatura, de acordo com relatos, geralmente se mantém agradável. É um ambiente pequeno e com precariedades em seus subsistemas (mobiliário) presentes. É uma estrutura antiga, apresentando algumas rachaduras nas paredes. 


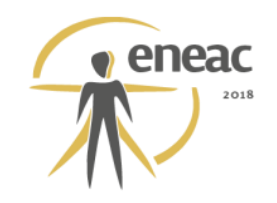

\subsection{Perfis de Usuários e Grupo de Ajuste}

O usuário especificado para a seguinte pesquisa é uma mulher idosa, 82 anos, com cerca de $1,60 \mathrm{~m}$ de altura e diagnosticada com Alzheimer. Seu nível de formação é o ensino fundamental incompleto, fora aposentada como trabalhadora rural. Possui o anseio de realizar atividades sozinha, mesmo que não seja bem executada. Além disso, possui algumas dificuldades por causa do envelhecimento, como baixa visão e perda de força muscular.

O Alzheimer tem três estágios, o primeiro estágio é de extrema importância, pois é nele que a doença deve ser identificada e tratada imediatamente, as chances dela não evoluir se for tratada desde o inicio são grandes, porém na maioria das vezes esse estagio é confundido com características comuns da velhice, e isso piora o quadro clinico, o paciente acaba entrando no segundo estagio, e não há cura, o tratamento estabiliza o quadro, o paciente não pioras significativas, mas também não tem melhora, por isso é importante o diagnostico precoce. No estágio avançado, a doença pode levar a pessoas a: ter dificuldades para comer, ficar incapacitada para comunicar-se, não reconhecer parentes, amigos e objetos, ter dificuldade para caminhar, ter dificuldade na deglutição.

\subsection{Análise da tarefa}

\subsubsection{Lavar as Mãos e Utilizar o armário suspenso}

Observando as posturas adotadas pela idosa durante a utilização do ambiente, são encontrados muitos problemas, algumas vezes devido a disposição dos elementos que compõem o ambiente ou por não serem adequados devido suas necessidades específicas.

Figura 2 - Uso da pia e armário suspenso.

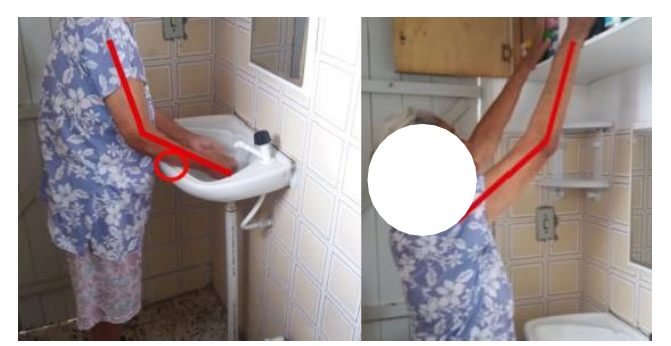

Fonte: Capturado pelos autores para a pesquisa.

Quando utiliza a pia a idosa relata problemas por falta de espaço. É preciso retirar as mãos da pia para poder esfregá-las e só então levar a mão para a pia novamente. Além disso, a torneira é muito difícil de rosquear, o seu antebraço fica em contato com a porcelana a qual, para ela, causa desconforto por ser fria e incômoda, chegando às vezes a machucá-la enquanto lava as mãos devido à fragilidade muscular e tegumentar do seu membro.

O armário suspenso encontra-se muito elevado forçando a idosa a estender seus membros superiores que ficam extremamente abduzidos, ela sente muito incômodo nos ombros e, por vezes, até nas costas e, por isso, ela tem evitado utilizar tal armário e pede para que alguém pegue seus objetos de higiene. Além disso, essa postura pode trazer riscos a idosa, que ao exercer um esforço físico maior queixa-se de se sentir tonta, podendo cair no chão. 


\section{(x) $^{\text {enack }}$}

\subsubsection{Uso do sanitário e box}

Ao utilizar o vaso sanitário percebe-se que não existem apoios próximos ao assento sanitário para a usuária sentar-se ou levantar-se. O assento sanitário é baixo, o que aumenta o esforço da idosa para abaixar-se. Outro ponto a ser observado é que a pouca iluminação natural que entra é direcionada para o seu campo visual, ofuscando-a.

Figura 3 - Simulação de uso do sanitário e box.

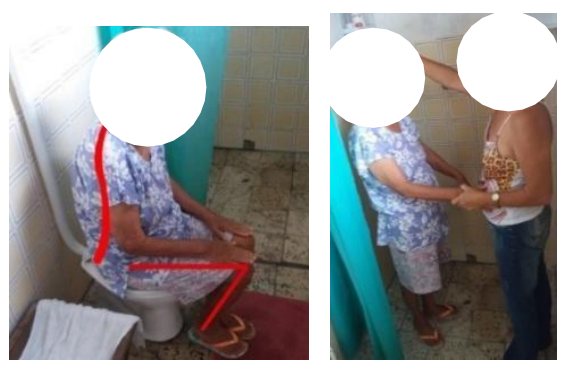

Fonte: Capturado pelos autores para a pesquisa.

No momento do banho, em conjunto com sua filha/cuidadora, é preciso que a idosa mantenha-se em pé dentro do box, molhando também a cuidadora pelo pouco espaço e pelo chuveiro não possuir uma ducha móvel, sendo fixado no meio da área molhada. Também não há nenhum tipo de assento para descanso ou barras de apoio.

\subsubsection{Considerações Antropométricas}

De acordo com Panero e Zelnik (2013), o alcance para idosos sofre uma grande variação se comparado ao alcance dos mais jovens. Além disso, essa variação pode ocorrer entre os próprios idosos em decorrência de problemas de mobilidades articulares frequentes nesta faixa etária. Desta forma, foram medidos as larguras, comprimentos e profundidade dos objetos dispostos no ambiente com o objetivo de verificar se as dimensões do ambiente estão de acordo com o que é recomendado e, caso não estejam, corrigi-las. A seguir há uma listagem das medidas de alguns componentes do banheiro e as recomendações antropométricas sugeridas por Panero e Zelnik (2013).

O lavatório tem uma altura suficiente, porém a profundidade é inferior ao recomendado, o que comprova a queixa da usuária que necessita fazer algumas atividades fora da pia. No espaço de circulação disponível entre a pia e a parede foi encontrada a medida de $77 \mathrm{~cm}$ e o ideal é de $121,9 \mathrm{~cm}$, o espaço é apertado e predispõe a acidentes. A altura do espelho e do armário está dentro dos limites propostos por Panero e Zelnik (2013).

Tabela 1 - Dados identificados no lavatório.

\begin{tabular}{|c|c|c|}
\hline \multicolumn{2}{|c|}{ LAVATÓRIO } \\
\hline AMBIENTE & MEDIDA OBTIDA & MEDIDA RECOMENDADA \\
\hline Espaço Livre Lavatório/Parede & $77 \mathrm{~cm}$ & $121,9 \mathrm{~cm}$ \\
\hline Altura do Lavatório & $91 \mathrm{~cm}$ & $81,3-91,4 \mathrm{~cm}$ \\
\hline Profundidade do Lavatório & $35 \mathrm{~cm}$ & $48,3-91,4 \mathrm{~cm}$ \\
\hline Altura do Espelho & $112 \mathrm{~cm}$ & $175,3 \mathrm{~cm}$ (máximo) \\
\hline Altura do armário & $170 \mathrm{~cm}$ & $175,3 \mathrm{~cm}$ (máximo) \\
\hline
\end{tabular}

Fonte: Elaborada pelos autores da pesquisa. 


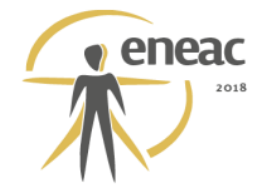

A altura da torneira do chuveiro é mais alta que o recomendado tendo $130 \mathrm{~cm}$ e o ideal de $101 \mathrm{~cm}$ a $127 \mathrm{~cm}$. As alturas do chuveiro e da saboneteira estão dentro dos limites estabelecidos. O espaço de livre circulação entre paredes no chuveiro é insuficiente tendo apenas $112 \times 102 \mathrm{~cm}$ e o recomendado é de $137,2 \mathrm{~cm}$. Esta realidade se agrava se levarmos em consideração que o ambiente é ocupado pela usuária idosa e sua acompanhante que sempre está presente no momento do banho. Outro fator que chama atenção é que não foram encontrados na área do chuveiro barras de apoio e um banco para banho. Estes dispositivos de segurança permitem que a usuária se sinta mais segura para realizar alguns movimentos naturais durante o banho.

Tabela 2 - Dados identificados na Área Molhada.

\begin{tabular}{|c|c|c|}
\hline \multicolumn{3}{|c|}{ ÁREA MOLHADA } \\
\hline AMBIENTE & MEDIDA OBTIDA & MEDIDA RECOMENDADA \\
\hline Espaço Livre entre Paredes & $112 \mathrm{~cm} \times 102 \mathrm{~cm}$ & $137,2 \mathrm{~cm}$ \\
\hline Altura da Torneira do Chuveiro & $130 \mathrm{~cm}$ & $101-127 \mathrm{~cm}$ \\
\hline Altura do Chuveiro & $201 \mathrm{~cm}$ & $182,9 \mathrm{~cm}($ mínimo) \\
\hline Altura do Banquinho (Banho) & Não existe & $30,5 \mathrm{~cm}($ mínimo) \\
\hline Largura do Banquinho (Banho) & Não existe & $38,1 \mathrm{~cm}$ \\
\hline Altura da Barra de Apoio & Não existe & $101,6-121,9 \mathrm{~cm}$ \\
\hline Altura da Saboneteira & $122 \mathrm{~cm}$ & $101,6-121,9 \mathrm{~cm}$ \\
\hline
\end{tabular}

Fonte: Elaborada pelo autores para a pesquisa.

Para verificar se o vaso sanitário está de acordo com o recomendado, foi levado em consideração a altura do suco poplíteo da mulher $5 \%$ il e foi obtido um resultado pouco acima do recomendado, porém, como uma idosa necessita de um assento mais elevado para facilitar na hora de levantar-se ou sentar-se, consideramos que um assento mais elevado seria o mais indicado. A papelaria está um pouco abaixo do recomendado.

Tabela 3 - Dados identificados no vaso sanitário.

\begin{tabular}{|c|c|c|}
\hline \multicolumn{3}{|c|}{ VASO SANITÁRIO } \\
\hline AMBIENTE & MEDIDA OBTIDA & MEDIDA RECOMENDADA \\
\hline Altura do Vaso & $36 \mathrm{~cm}$ & $35,6 \mathrm{~cm}$ (5\%il mulher) \\
\hline Espaço Livre - Vaso/Parede & $54 \mathrm{~cm}$ & $61 \mathrm{~cm}$ \\
\hline Altura da Papeleira & $51 \mathrm{~cm}$ & $76,2 \mathrm{~cm}$ \\
\hline
\end{tabular}

Fonte: Elaborada pelos autores para a pesquisa.

Para verificar as medidas da porta foi analisada a ABNT/CB 31; 31.999.99.001 de 2008 que trata sobre portas de madeira para edificações, e foram obtidos os seguintes resultados:

Tabela 4 - Dados identificados na porta e janela.

\begin{tabular}{|c|c|c|}
\hline \multicolumn{3}{|c|}{ PORTA / JANELA } \\
\hline AMBIENTE & MEDIDA OBTIDA & MEDIDA RECOMENDADA \\
\hline Largura da Porta & $57 \mathrm{~cm}$ & $60 \mathrm{~cm}-90 \mathrm{~cm}$ \\
\hline Altura da Porta & $184 \mathrm{~cm}$ & $210 \mathrm{~cm}$ \\
\hline Espessura da porta & $1,2 \mathrm{~cm}$ & $3,5 \mathrm{~cm}$ \\
\hline Altura da Janela & $150 \mathrm{~cm}$ & - \\
\hline
\end{tabular}

Fonte: Elaborada pelos autores para a pesquisa. 


\section{(x) $^{\text {enack }}$}

\subsubsection{Considerações sobre Conforto Ambiental}

A iluminação foi um dos problemas encontrados no ambiente analisado, uma vez que quando precária, pode prejudicar a visualização dos obstáculos do banheiro e quando demasiada pode causar confusão e ofuscamento. Segundo Pascale (2002) deve-se ter cuidado também com a iluminação desigual e irregular para que não cause reflexos de sombra e por ocasião possa dar a impressão de degraus ou falsos bloqueios, pois podem causar confusão no indivíduo e ocasionar agitação. Com o auxílio de um luxímetro devidamente calibrado, encontrou-se no ambiente os seguintes valores: às $7 \mathrm{~h} 30 \mathrm{~min}-75$ lux (com lâmpada apagada); às 19h30min - 160 lux (com lâmpada acesa). Segundo a recomendação NBR 5413/1992 para banheiros residenciais o nível adequado seria de 150 lux, podemos concluir a partir disto que a iluminação natural do ambiente durante o dia é insuficiente e à noite, após a utilização de iluminação artificial, fica acima do recomendado. Também devemos lembrar que no espaço existe apenas uma fonte de iluminação artificial, impedindo uma distribuição de iluminação em vários pontos distintos de atividades no espaço.

Se tratando de ventilação, o local analisado por ser pequeno e dispor de apenas um pequeno basculante para saída e entrada de ar, não foram encontradas correntes de vento, nem mudanças bruscas de temperatura durante o dia. Ficou constatado que, mediante as medições feitas, o ambiente está sem uma circulação de ar adequada. A pouca ventilação que entra é rara, chegando a atingir, em seu limite, $0,1 \mathrm{~m} / \mathrm{s}$ (aferição realizada com um anemômetro), mas apenas quando está ventando muito no ambiente externo. Contudo, a velocidade do ar considerada agradável é 0,1 e $0,2 \mathrm{~m} / \mathrm{s}$ em temperaturas próximas de $24^{\circ} \mathrm{C}$, acima dessa temperatura o indicado é 0,2 à $0,5 \mathrm{~m} / \mathrm{s}$ (IIDA, 2005). A aeração, segundo a NBR 6401 , o recomendável é que seja de $0,25 \mathrm{~m} / \mathrm{s}$ ou menos, o que nos faz entender que o ambiente está inadequado com relação a estes quesitos.

Com o auxílio de um decibelímetro, verificou-se que o local apresenta um ruído de $32 \mathrm{~dB}$ a $\mathrm{dB}$, dependendo de como o banheiro está sendo utilizado, quando está sem nenhuma ação humana chega a $32 \mathrm{~dB}$, porém ao utilizar a torneira ou o chuveiro passa a ter de $55 \mathrm{~dB}$ a 60 $\mathrm{dB}$. O nível de ruído está fora dos padrões aceitos se comparado aos valores indicados pela NBR 10152, a qual sugere para ambientes residenciais o valor de $40 \mathrm{~dB}$ a $50 \mathrm{~dB}$.

Segundo a NBR 6410 o recomendado para ambientes que dispõem de idosos é ter uma temperatura equivalente a $23,88^{\circ} \mathrm{C}$. No ambiente foram encontrados os seguintes valores: às $08 \mathrm{~h} 30 \mathrm{~min}-23^{\circ} \mathrm{C}$; às $12 \mathrm{~h} 30 \mathrm{~min}-26^{\circ}$; às $17 \mathrm{~h} 30 \mathrm{~min} 24^{\circ} \mathrm{C}$. Desta forma o banheiro pode ser considerado agradável no período da manhã, ficando acima do recomendado apenas no período da tarde, porém devido à falta de ventilação pode-se ter a sensação de abafado.

As cores do ambiente são o branco, o bege e o verde claro. Em se tratando de um idoso, é importante verificar que o uso de contrastes facilita a interação dele com os objetos. Desta forma faz-se necessário destacar a porta, o piso e os objetos da parede, pois otimizariam a visualização pelo idoso. Cabe lembrar também que se deve atentar para que se evite o uso de revestimentos que reflitam a iluminação do espaço ou causem ofuscamento.

Para verificar a circulação no banheiro, foi aplicado o Método MACHIA, o qual verificou que, enquanto uma pessoa está sentada no vaso sanitário, outra pessoa conseguiria ficar na área molhada ou transitar entre o vaso e a pia sem nenhum contato entre elas. A a valiação também nos fez perceber que a porta do ambiente tem uma abertura que exige atenção, podendo o indivíduo topar na parede. Foi possível perceber ainda que, ao se abrir a porta no momento em que alguém utiliza a pia, a porta e a pessoa no interior do banheiro sofrerão contato e possível acidente. Viu-se também que, caso a idosa esteja usando a privada, fica difícil transitar entre ela e a parede. Outro fator que chamou atenção foi que duas pessoas na área molhada apresentam situação de atenção, no entanto esta atividade é realizada com frequência para o banho da idosa. 


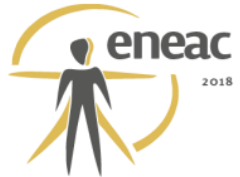

Figura 04 - Planta baixa do banheiro social

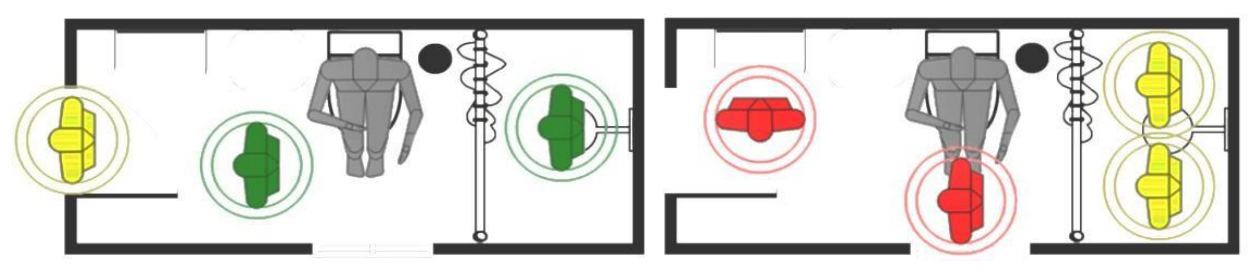

Fonte: Elaborado pelos autores para a pesquisa.

Os problemas começam a ficar evidentes nas ocasiões em que, hipoteticamente, a cuidadora não conseguiria entrar no banheiro sem esbarrar a porta na idosa no momento em que ela utilizasse a pia, assim como na hipótese da idosa estar no vaso e a cuidadora tivesse que chegar até o box tendo dificuldades de passar por ela para chegar ao local. É preciso atenção no momento em que a cuidadora estiver na área molhada junto à idosa. Desta forma é possível destacar: a falta de espaço dentro do box para que tanto a idosa como a cuidadora possam partilhar o espaço com mais conforto e mobilidade; a ausência de barras de apoio dentro do box (para que ela possa ter um ponto para sentar-se ou apoiarse) e em frente ao sanitário, para que ela possa usá-las para levantar-se, afinal a idade a faz perder tônus muscular; o baixo índice de iluminação no ambiente, principalmente dentro do box, o que dificulta a visibilidade de objetos; a presença de objetos elevados que exigem demasiado esforço por parte da idosa para alcançá-los.

\subsection{Adaptações às Necessidades dos Usuários}

A partir dos problemas encontrados foi possível estabelecer e sugerir contribuições delineadas através de procedimentos corretivos, a saber:

- Substituir a porta de acesso ao ambiente por um modelo maciço, forte e resistente, uma vez que indivíduos com Alzheimer tendem a perder o controle da intensidade da força aplicada a artefatos. Aplicar na porta uma cor que crie contraste com a parede e o mobiliário (destacando cromaticamente o puxador e fechadura), devido ao fato da crescente dificuldade de visualização e distinção de elementos em um mesmo plano e em planos alternados. Utilizar porta corrediça de dimensões $210 \times 90 \mathrm{~cm}$, atentando para a fixação de uma barra de apoio horizontal na face interna da porta;

- Aplicar contrastes cromáticos entre piso, paredes, louças e mobiliários. Evitar o uso de cores vibrantes e variadas, pois indivíduos com Alzheimer sentem transtornos e confusão face à presença de cores fortes e variadas demais;

- Aplicar sensores de captação do movimento para acionamento dos dispositivos do banheiro, como torneira e lâmpada, pois, com o tempo e gravidade da doença, indivíduos com Alzheimer perdem a familiaridade com o modo de uso de torneiras e interruptores;

- Unir o lavatório e o armário em um único mobiliário, em acréscimo, usar uma pia de dimensões maiores (cuba com pelo menos $50 \mathrm{~cm}$ de largura), uma vez que frequentemente surge a necessidade do indivíduo com Alzheimer fazer asseios parciais na pia ao longo do dia. Este armário que suportará a pia deve ser flutuante, fixado de modo que sua superfície tenha $90 \mathrm{~cm}$ de altura, com $45 \mathrm{~cm}$ de profundidade. $O$ armário superior deve ser fixado com sua base a $170 \mathrm{~cm}$ do piso acabado;

- O espelho deve ter dimensões pequenas, deve ser de vidro temperado e possuir película transparente em sua face frontal, uma vez que, em fases mais avançadas do Alzheimer, o indivíduo pode não se reconhecer nem se aceitar visualmente mais velho, fazendo-o tentar quebrar o espelho; 


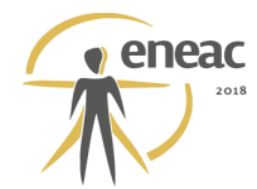

- Aplicar iluminação artificial indireta para todo o ambiente, assim como abaixo do móvel suspenso, diminuindo as sombras e evitando ofuscamento;

- Inserir cortina com tecido impermeável ao invés de box de vidro temperado, uma vez que confusões mentais repentinas (típicas do Alzheimer) podem ocasionar quedas (a cortina auxiliaria a apoiar e se sustentar, colaborando para a redução do impacto da queda);

- Instalar uma nova janela, de dimensão mínima de $1 \mathrm{~m}$ de largura (permitindo entrada de iluminação natural e aumento da circulação de ar interna no ambiente), em madeira (resistente) e com persianas móveis (que possam ser fechadas e abertas). A janela não deve permitir a abertura total da esquadria, pois muitas vezes o idoso com Alzheimer tem comportamentos de fuga;

- Aplicar um piso antiderrapante, pois frequentemente as confusões mentais repentinas fazem os idosos com Alzheimer terem falhas no equilíbrio e no tônus muscular. O piso deve ter baixo índice de refletância, para reduzir a incidência de estímulos a estas confusões;

- Instalar barras para apoio dentro da área do chuveiro, uma barra horizontal na parede lateral à parede do chuveiro, e uma barra vertical na saída da área de banho. Fixar barras na parede posterior ao vaso, ou ao próprio vaso, podendo ainda dispor de assento sanitário com barras próprias.

- Optar por assento sanitário com altura elevada, para facilitar o processo de sentar e levantar. Dispor de banquinho de apoio para os pés do idoso para facilitar a evacuação, pois indivíduos com Alzheimer apresentam frequentemente constipação, além de, em casos mais graves, dificuldades para evacuar por perda de familiaridade com o procedimento orgânico natural;

- Fixar um assento de banho dentro da área do chuveiro, para auxílio na hora da higiene, pois muitas vezes a inquietude do idoso com Alzheimer se revela bastante intensa;

- Introduzir um chuveiro flex, o qual é composto por uma ducha independente que permite a utilização manual por parte do cuidador. A base da ducha deve ser Instalada a $201 \mathrm{~cm}$ do piso acabado e sua chave a $105 \mathrm{~cm}$;

- Fixar a papeleira a 76,2 cm do piso acabado, preferencialmente em frente ao vaso. Posicionar um cesto de lixo ao lado da papeleira, facilitando a identificação do local de descarte.

Através das recomendações ergonômicas, foi possível chegar a um projeto conceitual que guiasse visualmente a composição do um novo ambiente, orientando a família residente no local do estudo de caso. O projeto conceitual foi detalhado e entregue impresso à família, juntamente com a oferta de apoio gratuito no acompanhamento da realização das adequações. A proposta de reforma foi aceita pela família e o processo de reestruturação está em fase inicial. Ao término das alterações no espaço, uma nova avaliação no ambiente será realizada, sob o foco de verificação do índice de adequação ergonômica do projeto executado.

Neste momento, poderão ser observados alguns pontos como a iluminação, o novo piso antiderrapante com baixo índice de refletância e a porta corrediça com uma cor vibrante. $O$ contraste das cores também foi aplicado entre a porta, o piso, a cortina e a área molhada com o intuito de melhorar a visibilidade das partes pela idosa.

No interior do box foram inseridas as barras de apoio, o assento para banho, que é retrátil devido a falta de espaço, e uma ducha para a cuidadora dar banho na idosa sem se molhar. A iluminação natural também foi melhorada a partir da ampliação da janela. A cortina feita de tecido impermeável e mais resistente, em caso de quedas poderá oferecer apoio. 


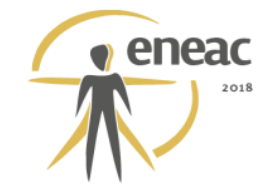

Figura 5 - Vista superior cotada.

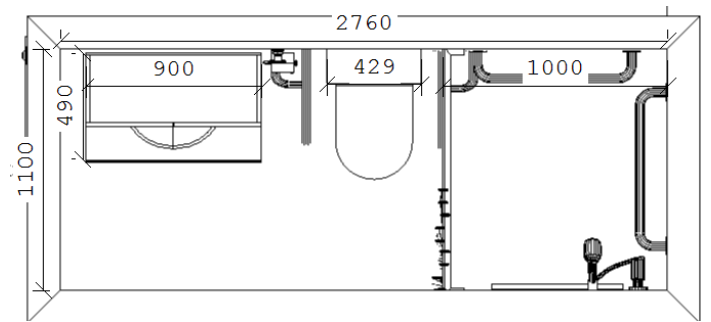

Fonte: Elaborado pelos autores para a pesquisa.

Figura 6 - Rendering \#01 e \#02
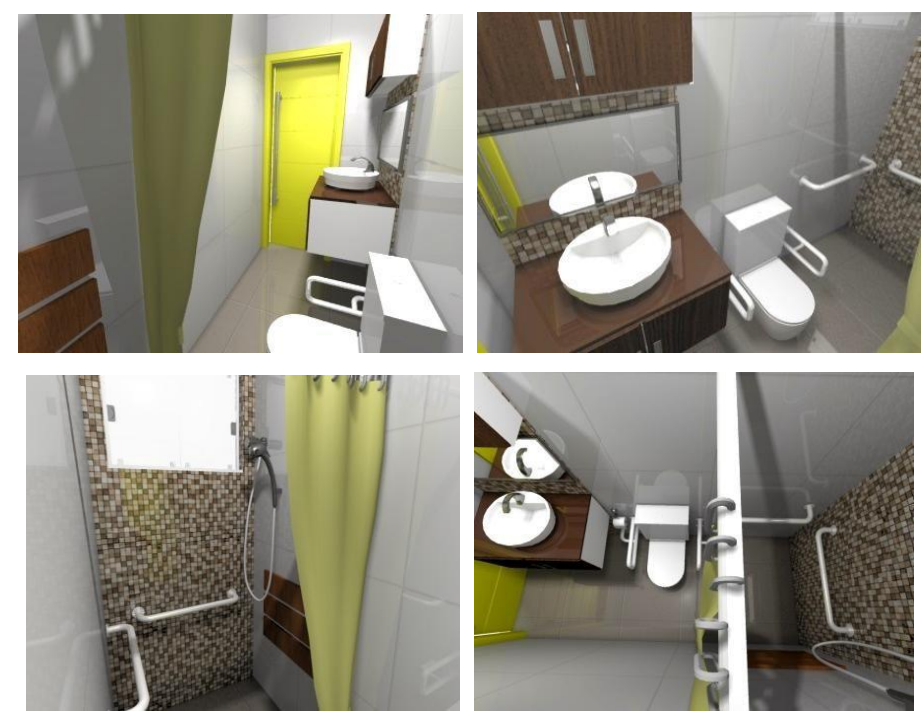

Fonte: Acervo próprio

\section{CONCLUSÃO}

Com o avanço da idade, o idoso acaba sujeito a disfunções de ordem muscular e osteoarticular, as quais afetam, entre outras coisas, a sua capacidade de equilíbrio, força e amplitude de alcance, exigindo atenções especiais voltadas para sua segurança, principalmente se o ambiente trouxer riscos de acidentes, como é o caso de um banheiro. Quando falamos de um idoso acometido por Alzheimer, essa situação se torna ainda mais especial, uma vez que, dependendo do grau da doença, o idoso perde a capacidade de abrir portas ou encontrar objetos quando inseridos em ambientes já não ais familiares ou visualmente confusos (quantidade de elementos, excesso de cores e contrastes ou ausência de contraste).

Sobre as dificuldades enfrentadas pela idosa a qual se refere esta pesquisa, percebemos que a maioria dos problemas encontrados no banheiro trariam transtornos para qualquer idoso, mas a presença do Alzheimer nos fez atentar para demandas bastante específicas. Outro ponto que nos leva a refletir é que, em muitos casos, a adaptação do ambiente pode se revelar mais complexa, assim como no caso proposto, devido à falta de espaço, não seria possível ampliá-lo. Alterar a altura do armário, inserir barras de apoio, alterar a forma de abertura da porta e inserir um banco para melhor acomodar a idosa na hora do banho, são medidas simples, mas se revelam como diferencial para sua segurança. Elementos 


\section{(x) $^{\text {enack }}$}

específicos como a presença de contrastes e uso de poucas cores; a presença de um banquinho para auxílio na evacuação; um espelho de pequena dimensão em vidro temperado e com fixação de película se destacaram no que diz respeito às necessidades específicas de pessoas com Alzheimer.

Esta pesquisa nos fez perceber que projetar para um idoso com Alzheimer vai muito mais além do que simplesmente pensar nas limitações naturais decorrentes do envelhecimento, existem de fato necessidades específicas decorrentes desta doença e que são fundamentais para um melhor uso do espaço.

\section{REFERÊNCIAS BIBLIOGRÁFICAS}

ASSOCIAÇÃO Brasileira de Alzheimer. Disponível em: <http://abraz.org.br/sobrealzheimer/evolucao-da-doenca>. Acesso em: 09 jun. 2017 às 17h10min.

ASSOCIAÇÃO BRASILEIRA DE NORMAS TÉCNICAS. NBR 31: 999.99.001: Portas de madeira para edificação. Rio de Janeiro. 2008.

ASSOCIAÇÃO BRASILEIRA DE NORMAS TÉCNICAS. NBR 10152: Níveis de ruído para conforto acústico. Rio de Janeiro. 1987.

ASSOCIAÇÃO BRASILEIRA DE NORMAS TÉCNICAS. NBR 5413: Iluminância de Interiores: procedimento. Rio de Janeiro. 1992.

ASSOCIAÇÃO BRASILEIRA DE NORMAS TÉCNICAS. NBR 6401: Instalações Centrais de Ar Condicionado para Conforto. Rio de Janeiro. 1980.

ATTAIANESE, Erminia. DUCA, Gabriella. Human factors and ergonomic principles in building design for life and work activities: an applied methodology. Theoretical Issues in Ergonomics Science, 13:2, p. 187-202, 2010.

BARROS, Bruno. Avaliação Antropométrica de Espaços de Circulação Interna de Ambientes: um método proposto. In: CIPED-2009: Congresso Internacional de Pesquisa em Design, Bauru, São Paulo, 2009.

IIDA, Itiro. Ergonomia: Projeto e Produção. 2. ed. São Paulo: Edgard Blucher, 2005. 630p. PANERO, Julius. ZELNIK, Martin. Dimensionamento Humano para Espaços Interiores. Barcelona, Editorial Gustavo Gili/GG, 2013. 320p.

PASCALE, M. A. Ergonomia e alzheimer: a contribuição dos fatores ambientais como recurso terapêutico nos cuidados de idosos portadores da demência do tipo Alzheimer. 2002. $120 \mathrm{f}$. Dissertação (Pós-Graduação em Engenharia de Produção) - Universidade Federal de Santa Catarina, Florianópolis. 2002.

SILVA, Andrielly Roseane da; BARROS, Bruno Xavier da Silva. Cozinhas e idosos com alzheimer: um estudo teórico com foco no norteamento adaptativo do ambiente, p. 553-562. In: Anais do VI Encontro Nacional de Ergonomia do Ambiente Construído \& VII Seminário Brasileiro de Acessibilidade Integral [=Blucher Design Proceedings, v.2 n.7]. São Paulo: Blucher, 2016.

SMITH, M.; BUCKWALTER, K. Behaviors associated with dementia. American Journal of Nursing. v. 105 , n. 7, p. 40-52, jul., 2005.

SOUSA, Isabella Gaspar; MAIA, Ivana Márcia Oliveira. Arquitetura de interiores em ambientes para idosos portadores da doença de Alzheimer. Arq.Urb, v. 11, p. 192-207, 2014. 